\title{
SABERES CONSTRUÍDOS NA EXPERIÊNCIA E FORMAÇÃO DOCENTE
}

\author{
Rafaelly Galindo dos Santos Pereira ${ }^{1}$, Renata de Oliveira Cartaxo ${ }^{2}$, \\ Herika de Arruda Mauricio ${ }^{3}$, Pedro Henrique Sette-de-Souza ${ }^{4}$
}

\section{RESUMO}

O objetivo do estudo foi analisar a percepção dos professores sobre os saberes construídos na experiência e formação docente. Trata-se de um estudo qualitativo, analítico-observacional. A população do estudo foi composta pelos professores do curso de bacharelado em Odontologia que possuíam vínculo com a Universidade de Pernambuco, campus Arcoverde no ano de 2016. Do total de dez professores, oito aceitaram participar da pesquisa. As entrevistas foram feitas com base em questionário aberto, sendo a entrevista gravada e transcrita. Os professores entrevistados responderam quatro questões norteadoras bem como um questionamento acerca dos recursos de trabalho. A análise desse conteúdo foi realizada e, posteriormente, elaborado o Discurso do Sujeito Coletivo. Os resultados encontrados no presente estudo sugerem que professores identificam atitudes/posturas/elementos de alguns dos seus antigos professores em suas práticas atuais. É possível concluir que os professores transmitem em suas práticas pedagógicas experiências vividas enquanto acadêmicos, além de autoidentificarem atitudes e posturas de seus antigos professores.

Palavras-chave: Docentes de Odontologia. Formação profissional. Educação continuada. Educação superior.

\section{Como citar este documento - ABNT}

PEREIRA, Rafaelly Galindo dos Santos; CARTAXO, Renata de Oliveira; MAURICIO, Herika de Arruda; SETTE-DE-SOUZA, Pedro Henrique. Saberes construídos na experiência e formação docente. Revista Docência do Ensino Superior, Belo Horizonte, v. 10, e021722, p. 1-14, 2020. DOI: https://doi.org/10.35699/22375864.2020.24717.

Recebido em: 23/06/2020 Aprovado em: $27 / 08 / 2020$ Publicado em: 28/11/2020

\footnotetext{
${ }^{1}$ Universidade de Pernambuco, campus Arcoverde (UPE-Arcoverde), Arcoverde, PE, Brasil. ORCID ID: https://orcid.org/0000-0002-7859-6890. E-mail: rafaellygalindosm@gmail.com. ${ }^{2}$ Universidade de Pernambuco, campus Arcoverde (UPE-Arcoverde), Arcoverde, PE, Brasil. ORCID ID: https://orcid.org/0000-0002-6720-0897. E-mail: renata.cartaxo@upe.br.

${ }^{3}$ Universidade de Pernambuco, campus Arcoverde (UPE-Arcoverde), Arcoverde, PE, Brasil. ORCID ID: https://orcid.org/0000-0002-6645-457X. Email: herika.mauricio@upe.br. ${ }^{4}$ Universidade de Pernambuco, campus Arcoverde (UPE-Arcoverde), Arcoverde, PE, Brasil. ORCID ID: https://orcid.org/0000-0001-9119-8435. E-mail: pedro.souza@upe.br.
} 


\section{CONOCIMIENTOS BASADOS EN LA EXPERIENCIA Y LA FORMACIÓN DE LOS PROFESORES}

\section{RESUMEN}

El objetivo del estudio fue analizar la percepción de los profesores sobre el conocimiento basado en la experiencia y la formación de los profesores. Este es un estudio cualitativo, analítico-observacional. La población de estudio estaba compuesta por profesores de la carrera de Odontología afiliados a la Universidad de Pernambuco, campus Arcoverde, en 2016. Del total de diez profesores, ocho acordaron participar en la investigación. Las entrevistas se realizaron en base a un cuestionario abierto, la entrevista se grabó y transcribió. Los profesores entrevistados respondieron a cuatro preguntas orientadoras, así como a una pregunta sobre los recursos laborales. Se realizó el análisis de este contenido y, posteriormente, se elaboró el Discurso del Sujeto Colectivo. Los resultados encontrados en este estudio sugieren que los maestros identifican actitudes/posturas/elementos de algunos de sus antiguos maestros en sus prácticas actuales. Se puede concluir que los maestros transmiten experiencias vividas como eruditos en sus prácticas de enseñanza, además de las actitudes y posturas de autoidentificación de sus antiguos maestros.

Palabras clave: Docentes de Odontología. Capacitación profesional. Educación continua. Educación superior.

\section{KNOWLEDGE BUILT BASED ON EXPERIENCE AND TEACHER TRAINING}

\section{ABSTRACT}

The objective of the study was to analyze teachers' perception of knowledge built on experience and teacher training. It is a qualitative, analytical-observational study. The study population was composed of Bachelor of Dentistry Teachers who had links with the University of Pernambuco, Arcoverde campus, in the year 2016. Out of a total of ten teachers, eight agreed to participate in the research. The interviews were conducted based on an open questionnaire, with the interview recorded and transcribed. The interviewed teachers answered four guiding questions as well as one question about the work resources. The analysis of this content was carried out, and later, the Collective Subject Speech was elaborated. The results found in this study suggest that teachers identify attitudes/postures/elements of some of their former teachers in their current practices. It is possible to conclude that teachers transmit experiences lived as scholars in their pedagogical practices, besides self-identifying their former teachers' attitudes and postures.

Keywords: Dentistry teachers. Professional training. Continuing education. Higher education. 


\section{INTRODUÇÃO}

A produção de conhecimento confirma a principal diferença entre animais racionais (humanos) e os outros, o que coloca os primeiros numa posição favorecida na liderança do mundo e da história (NORO, 2015). Raciocinar sobre a formação, impreterivelmente, delega a necessidade de identificar as principais estratégias a serem referenciadas para que ocorra o aprendizado, um entrelaçamento entre informações (SOARES; CUNHA, 2010).

O modelo do docente porta-voz preocupado apenas em ensinar os preceitos passados como verdade absoluta e dos discentes preocupados apenas em memorizar esses conceitos e fatos, sem uma análise crítica das informações, não mais atende a necessidade da sociedade contemporânea. É preciso o entendimento de conhecer o estudante e sua cultura a fim de possibilitar-Ihes uma aprendizagem significativa e uma formação profissional voltada para o enfrentamento crítico dos problemas da sociedade (SOARES; CUNHA, 2010). Decorar preceitos, leis e regras são modelos de aprendizagem mecânica, e seu esquecimento sucede pouco tempo após a memorização (HILGER, 2016).

Nessas circunstâncias, o professor assume uma grande responsabilidade, cabendo a ele não apenas a passagem de conhecimentos, mas também a provocação no aluno da consciência crítica e da análise da realidade que os cercam (NORO, 2015). Em meados da década de 1980, ganharam força, no cenário internacional, discussões sobre a formação dos professores de educação superior. O estudo para o avanço da qualidade da atuação do professor universitário há muito vem sendo analisado com objetivo de buscar melhorias no interior das próprias universidades, levantando questionamentos do papel da educação sobre o docente (CUNHA, 2013).

A investigação acerca do processo de formação docente, inicial e continuada, pode colaborar com o entendimento das práticas pedagógicas realizadas por aquele que ensina na educação profissional. Logo, deve-se aliar a essa lógica a ideia de que o docente é reflexo das próprias vivências experimentadas ao longo do processo formativo contínuo. Dessa maneira, como a formação do docente e a história pessoal pode afetar as práticas pedagógicas? Portanto, o objetivo deste estudo foi analisar a percepção dos professores sobre os saberes construídos na experiência e formação docente.

\section{PERCURSO METODOLÓGICO}

Neste estudo, foram utilizados métodos de pesquisa qualitativa no qual os investigadores analisaram as falas dos participantes sem que houvesse qualquer intervenção. Por se tratar de um grupo pequeno e conhecido, incluiu-se como população do estudo: professores do curso de bacharelado em Odontologia da Universidade de Pernambuco (UPE) campus Arcoverde, que possuíam vínculo ativo com a instituição no ano de 2016 , sem levar em 
consideração o tempo de docência ou a formação. Dessa população, excluiu-se aqueles que passaram por processo de mobilidade interna/afastamento no ano de 2016.

Do total de 13 professores integrantes do corpo docente, dez se enquadravam nos critérios de elegibilidade, e oito aceitaram participar da pesquisa. As entrevistas foram feitas entre março e outubro de 2017, período pelo qual a faculdade passava por uma paralisação por problemas de infraestrutura, havendo a necessidade de um tempo maior para finalizar as entrevistas. A pesquisadora Rafaelly Galindo dos Santos Pereira realizou as entrevistas com os professores, tendo feito um treinamento prévio sobre técnicas de coleta com o professor Pedro Henrique Sette-de-Souza, tanto para conduzir as entrevistas como para a posterior transcrição do material. As entrevistas foram realizadas em uma sala de aula da própria instituição onde somente a entrevistadora e o professor estavam presentes. Cada entrevista durou, em média, 20 minutos.

Os professores entrevistados responderam quatro questões norteadoras, que objetivaram compreender um pouco mais de sua história pessoal e como ela reflete em sua vida acadêmica, bem como um questionamento acerca dos recursos de trabalho. As indagações lançadas aos professores foram:

1. Como você acredita que sua experiência, enquanto era estudante, está sendo refletida na sua prática profissional de educador?

2. Você identifica em suas atitudes/posturas elementos de alguns dos seus antigos professores?

3. Você teve alguma preparação antes de ir para sala de aula? Como foi?

4. Em sua concepção, os recursos que você tem para trabalhar o aprendizado do estudante são suficientes? Em que pode melhorar?

Logo após a entrevista, realizou-se a transcrição manual dos áudios dos docentes para um software de texto. A partir de então, para a realização desta avaliação, foi utilizada a técnica do Discurso do Sujeito Coletivo (DSC) (LEFEVRE; LEFEVRE, 2005), que é uma proposta de organização e tabulação de dados qualitativos de natureza verbal, obtidos dos depoimentos transcritos dos professores. A técnica consiste, basicamente, em analisar o material verbal coletado, extraído de cada uma das respostas, selecionando as expressões-chave (significado das falas), que são trechos mais significativos das respostas para poder reunir pensamentos e opiniões individuais em torno de uma ideia coletiva. A partir dessa análise, os trechos destacados foram reunidos para organização das falas em um discurso-síntese único. Para essa etapa, não se utilizou qualquer software específico para análise de discursos. Assim, construiu-se o discurso que representa a coletividade (DSC) para cada uma das questões propostas. O estudo foi submetido ao comitê de ética em pesquisa da UPE, sendo aprovado sob o parecer de no 2.156.454 (CAAE 68511617.5.0000.5207). Portanto, todos os sujeitos 
leram e assinaram o Termo de Consentimento Livre e Esclarecido anteriormente à participação na pesquisa.

\section{RESULTADOS E DISCUSSÃO}

De maneira geral, avaliar a prática docente é um desafio para a qualificação do ensino profissional e superior, tendo em vista que o docente de hoje reproduz, em muitos casos, a experiência tida quando ainda era estudante. Logo, pode-se entender que a docência, nesses casos, nada mais é do que a consequência de algumas experiências, uma simples repetição de atividades passadas. Contudo, o docente ainda é tão desvalorizado, que primeiro se é engenheiro, biólogo, geólogo etc. e só depois vem o papel de professor, tornando ambígua a profissão (TARDIF, 2000) e fortalecendo a ideia de que todo aquele possuinte de excepcional prática profissional será/seria excelente professor. Essa discussão é importante para fomentar a reflexão sobre esse dilema a fim de estabelecer algum referencial para o desenvolvimento docente propriamente dito (BATISTA, 2015).

Pesquisar sobre a influência do docente na vida acadêmica do aluno representa, no ensino superior, a importância de que o professor tem ao exercer sua função, em não apenas passar o conteúdo, mas em despertar, no aluno, a visão crítica. Além dos desafios apresentados pela instituição, os quais demandam qualificação, preparação e boa atuação, talvez o maior deles seja a preocupação e a necessidade do profissional, atuante na área do magistério, desenvolver a própria identidade (PRYJMA; OLIVEIRA, 2016).

Dos 10 professores que se enquadravam nos critérios de elegibilidade, oito professores aceitaram participar da pesquisa. Dentre eles quatro (50\%) eram do "ciclo básico" e quatro (50\%) do "ciclo profissionalizante", sendo quatro mulheres (50\%) e quatro homens (50\%), três doutores $(37,5 \%)$ e cinco mestres $(72,5 \%)$. Nenhum dos entrevistados residia no local do trabalho, necessitando deslocar-se semanalmente.

Os professores do curso de Odontologia foram submetidos a quatro perguntas nesse estudo. Ao serem perguntados se eles acreditavam que sua experiência, enquanto eram estudantes, está sendo refletida em sua prática profissional e educadora, os professores relatam, através do DSC-1, que:

Durante a graduação você faz um acúmulo de conhecimento. $O$ conhecimento não é só o que você recebe, mas como você o recebe. Era isso que eu admirava em alguns professores, a forma de lidar com o assunto/estudante, de passar o assunto. Então, eu me espelho nas boas, como trazer para a realidade o que acontece realmente na Odontologia, $e$ nas más experiências que tive durante a minha formação para tentar reproduzir as boas e eliminar o que achei ruim. Além de aperfeiçoar, ampliar a relação ensino-aprendizagem do aluno [DSC-1]. 
Com base no DSC-1, percebe-se que as boas experiências vividas pelos docentes enquanto estudantes tendem a ser reproduzidas e as más excluídas. Esse ciclo alicerça-se nas práticas historicamente construídas, delineando representações da profissão de professor que se estabelecem no senso comum. É um processo bastante presente na docência universitária, que leva o docente a repetir práticas naturalizadas na sua cultura (CUNHA, 2013). O saberfazer profissional, retratado em várias teorias, configura a característica profissional e o princípio de que os professores aprendem a ensinar através da experiência (JUNGES; BEHRENS, 2015).

A aproximação do conteúdo, principalmente, nos semestres iniciais, com a odontologia ou com o dia a dia clínico faz com que os estudantes se interessem mais pela aula (NORO, 2015). O simples fato de o professor conseguir fazer a relação do que está sendo visto em sala de aula com o processo de formação do estudante, transforma o assunto "maçante" em algo significativo. Isso faz com que, enquanto estudante, ele se empenhe mais por considerar que aquele conhecimento seria utilizado no futuro e, por consequência, quando docente, ele reproduz essa mesma atitude de associar teoria com prática para seus alunos (NORO et al., 2015).

Enquanto eram estudantes, os docentes entrevistados notavam que essa aproximação com uma possível realidade despertava neles um maior interesse. Assim sendo, tendem a repetir esses padrões comportamentais a fim de manter relação entre o que é aprendido na universidade com a realidade profissional. Todavia, é fundamental o uso de metodologias ativas de ensino-aprendizagem que permitam a construção do conhecimento baseados em problemas da realidade bem como integrar os conteúdos básicos e profissionalizantes, teóricos e práticos para superar os limites da formação e das práticas clínicas tradicionais (FEUERWERKER; SENA, 2002).

A soma da habilidade didática do professor universitário com o compromisso do aprendizado dos discentes leva ao entendimento do ensino e da aprendizagem como faces interdependentes. Quando o ensino e a aprendizagem não caminham lado a lado, os professores se preocupam em ensinar e não se os alunos aprenderam. Declaram que, se os alunos não aprenderam, a responsabilidade é inteiramente deles, porque não se dedicaram o suficiente (JUNGES; BEHRENS, 2015).

Quando questionados acerca da relação entre o professor e o estudante como determinante no processo de reprodução de aprendizagem, os professores afirmam que:

Você tem seus professores da época, como suas referências, tanto referências boas como referências ruins. Então, é comum que você acabe sendo influenciado por eles na sua forma de agir, de ensinar, de cobrar, se espelhando em professores que você admirava na graduação e pósgraduação, filtrando aquelas atitudes/posturas que seus professores faziam 
na sua época de estudante que você não achava legal. Assim, você procura não adotar, não reproduzir, acaba descartando-as [DSC-2].

Outra característica bastante significativa dentro da pesquisa, citada pelos docentes, foi a relação entre o professor e o estudante como determinante no processo de reprodução de aprendizagem. Para os docentes, ele reflete atitudes e posturas de professores da sua época com os quais ele possuía uma empatia (NORO et al., 2015). Assim, verifica-se que para reproduzir algo é importante um vínculo que aproxime os atores do processo (professores e estudantes). Entre os vários ambientes de ensino, as relações entre professores e estudantes despontam como uma das principais matrizes de interação na qual se apresentam valores, comportamentos e afetos que são veiculados subliminarmente durante a transmissão de conhecimentos e técnicas, e vão participando da construção da atitude profissional (RIOS; SCHRAIBER, 2012). Em nosso estudo, esse contato entre docentes e discentes pode ser observado no DSC-2.

Os resultados encontrados no presente estudo, por meio do DSC-2, sugerem que professores identificam atitudes, posturas e elementos de alguns dos seus antigos professores. O alicerce em experiências vividas por outros professores não é ruim, pelo contrário, são elementos que acrescentam à formação de um docente e o constroem, porque conviver com pessoas e compartilhar tais experiências amplia a bagagem de conhecimentos (NORO et al., 2015). Todavia, é preciso que, além disso, o professor alie os próprios conhecimentos ao maior número de ferramentas possíveis, que determine questionamentos, dinâmicas e diálogos. É necessário, pois, que o professor seja uma ponte entre o conhecimento e o estudante, instigando-o a procurar respostas, a valorizar a dúvida, o espanto, a curiosidade e, acima de tudo, estimulando o estudante a pensar (VOCHIKOVSKI et al., 2018). Ainda nesse sentido, o docente deve motivar os estudantes, tentando aproximar, sempre que possível, o conhecimento acadêmico com a realidade vivida (SETTEDE-SOUZA, 2020). Assim sendo, o professor ao revisitar todo o seu processo formativo e profissional deve se perceber enquanto engrenagem essencial de todo o processo de aprendizagem, embora não seja a peça central. Como exposto na fala de DSC-2, isso fará com que o docente autoperceba seu papel, separando o que poderia ou não ser replicado a partir de suas experiências pessoais.

No tocante a formação recebida em cursos de pós-graduação, os docentes relatam que (DSC-3):

Durante o mestrado, algumas disciplinas são ofertadas para prática de ensino, vivenciar a docência, metodologias de ensino que poderiam ser utilizadas e que os alunos poderiam se adequar melhor a elas. Apresentação de seminários, de como se portar, como dar aulas aos colegas do mestrado e professores, então isso acaba sendo um treinamento didático. Além do que a própria vivência em congressos, como preparação de slides, tempo de 
apresentação e oratória ajuda a essa preparação antes de ir para sala de aula [DSC-3].

Mesmo com o aprofundamento das discussões acerca da temática, o ensino bancário ${ }^{5}$ ainda continua presente. Embora os cursos de mestrado sejam considerados, atualmente, o principal meio institucional de preparação de professores para o ensino superior, eles não contemplam, de modo geral, a formação pedagógica. A Coordenadoria de Aperfeiçoamento de Pessoal para o Ensino Superior (CAPES) estabelece o tempo médio de dois anos para a conclusão de um curso de mestrado. Sendo assim, torna-se difícil para um candidato ao grau de mestre ter que cursar disciplinas de caráter didático-pedagógico além das disciplinas correspondentes ao próprio centro de interesse e, ao mesmo tempo, desenvolver as atividades necessárias para a conclusão da pesquisa (GIL, 2005). Em nosso estudo, a temática fica evidente quando se perguntou aos docentes como foi a preparação que eles receberam antes de entrar em sala de aula, a qual não conta com momentos teóricopráticos sobre o processo ensino-aprendizagem, como pode-se observar no DSC-3.

Como dito outrora, observa-se uma constante mudança no ensino, com uma tendência de rompimento do modelo tradicional no qual o professor ainda é o elemento central do processo ensino-aprendizagem. Essa mudança vem ocorrendo porque os docentes estão incorporando práticas inovadoras e facilitadoras (MORAES et al., 2018) que visam a autonomia do discente. Pesquisas demonstram que a formação docente é voltada para a pesquisa, enquanto a prática pedagógica reflexiva, fundamental ao professor, é novidade ao docente iniciante. Tal prática baseia-se em analisar o próprio trabalho a fim de entender pontos positivos e negativos, identificando e resolvendo problemas. Consequentemente, a formação de professores precisaria possuir dispositivos específicos que objetivassem formar profissionais reflexivos quanto à prática do ensino (PEREIRA; NASCIMENTO, 2016).

Assim, a avaliação do programa de qualquer curso deve, obrigatoriamente, conter em sua sistemática a avaliação docente, transformando o professor em sujeito do conhecimento a ser produzido (FREIRE, 1999). Entretanto, alguns autores chamam atenção para o equívoco de atribuir, ao professor, toda a responsabilidade por modificar o panorama da formação superior e profissional (SADALLA et al., 2000). É nesse contexto de corresponsabilização que o entendimento da formação profissional como um processo é capaz de desenvolver práticas reflexivas embasadas na vivência do docente (CHISM; LEES; EVENBECK, 2002).

\footnotetext{
${ }^{5}$ Ensino "tradicional" em que o aprendiz é visto como um recipiente vazio e o professor apenas o enche de conteúdo, sem que haja preocupação quanto a problematização, consciência, e autonomia, fatores tão envolvidos no processo de ensino-aprendizagem (FREIRE, 1999).
} 
O professor deve assumir um papel central nas problemáticas de investigação. Ademais, deve ser estimulado à produção autobiográfica ${ }^{6}$ como parte de sua formação profissional, transformando a experiência em conhecimento científico (CAVACO, 1999). Essa estratégia possibilita, ao docente, a compreensão de seu contexto e interação social, além de estabelecer novas relações com o "ensinar" (ROSSI; HUNGER, 2012).

Quando questionados sobre a importância de recursos gerais para o processo de ensinoaprendizagem, formou-se o seguinte discurso com base na resposta dos docentes (DSC-4):

Os recursos não são suficientes, acho que a gente sempre precisa ter as melhores condições pra poder ofertar a esses estudantes todos os tipos de estímulos, e isso reflete em vários aspectos, inclusive no rendimento dos alunos, recursos financeiros pra projetos, recurso humano, recurso físico. $A$ questão da infraestrutura, uma boa internet que não temos. Mas é claro que isso não é impedimento para se dar uma boa aula e transmitir conhecimento. $E$ que merecemos mais recursos e nossos estudantes também [DSC-4].

Apesar de serem parte primordial do processo, apenas os recursos humanos (os docentes e discentes) não bastam para o estabelecimento adequado do processo ensino-aprendizagem. Os recursos físicos e disponibilidade de ferramentas, alinhados a metodologias ativas que buscam autonomia dos sujeitos, auxiliam e facilitam a aprendizagem significativa dos estudantes. Isso se reflete na fala do DSC-4, que versa sobre os recursos necessários para a prática. Dito isso, sobre as dificuldades encontradas pelo docente neste estudo, como o ambiente físico e a falta de recursos, vale ressaltar que a universidade passava por um período de estruturação, com o campus onde o curso funciona ainda em fase de construção. Nessa época, as atividades de ensino eram realizadas em ambientes provisórios. Logo, o docente estando presente em ambiente de trabalho deficiente com a falta de recursos humanos e materiais e esgotamento físico possibilita um estresse psicológico do educador (ESTEVE, 1999). Nessa resposta, considerando-se que a pesquisa foi conduzida em uma universidade pública, todos esses fatos apontados representam motivos que podem ocasionar sobrecargas de trabalho físico e mental. Dessa forma, essa sobrecarga poderia impactar na satisfação quanto ao trabalho/ensino, saúde e bem-estar dos docentes e discentes (MARTINEZ; PARAGUAY; LATORRE, 2004).

Cabe destacar que esse é um estudo inicial no entendimento dos saberes construídos a partir da experiência e formação docente. O número reduzido de docentes e a frágil infraestrutura que o curso possuía no momento do estudo podem ter influenciado, de alguma forma, os resultados ora apresentados. Entretanto, o maior aprofundamento nas memórias e, até mesmo, em um estudo autobiográfico, com esses docentes, acerca da sua

\footnotetext{
${ }^{6}$ Narrativa autobiográfica capaz de levar a reflexões a partir de experiências vividas e, dessa forma, produzirem conhecimento (CECIM; STRAFORINI, 2018).
} 
vivência e formação para o ensino superior, ampliaria a compressão da importância desse aspecto (o da experiência enquanto processo formativo) na formação docente. Todavia, a grande fortaleza de nosso estudo reside no fato de ser um dos primeiros trabalhos no campo do ensino odontológico a abordar como a autopercepção dos saberes construídos pelos docentes ao longo de sua formação pode influenciar as próprias práticas pedagógicas.

Nesse sentido, apresentamos ao longo do texto algumas dimensões possíveis para explorar a temática. Assim, espera-se que, a partir deste estudo, os leitores e/ou pesquisadores da área assumam outras possibilidades para repensar este campo, de tal forma que o conhecimento possa ser construído, desconstruído e reconstruído. Pensar o processo é pensar tanto no discente quanto no docente, e, aqui, trazemos elementos para subsidiar futuras discussões dessa temática.

\section{CONSIDERAÇÕES FINAIS}

Considerando as elucidações dos participantes da presente pesquisa, é possível concluir que os professores transmitem experiências vividas enquanto acadêmicos nas próprias práticas pedagógicas, além de autoidentificarem atitudes e posturas de seus antigos professores. Durante a trajetória acadêmica, os docentes são expostos a diversos desafios e dificuldades, existindo uma preocupação em tornar efetiva a aprendizagem dos discentes. A fim de superar as adversidades, os professores necessitam desenvolver habilidades específicas, em especial, a capacidade didática. Cabe reforçar a importância da formação continuada do docente, responsável por tornar esse processo mais crítico e menos intuitivo, contribuindo para a formação de um novo saber educativo.

\section{REFERÊNCIAS}

BATISTA, Nildo Alves. Desenvolvimento docente na área da Saúde: uma análise. Trabalho, Educação e Saúde, Rio de Janeiro, v. 3, n. 2, p. 283-294, 2015. Disponível em: https://www.scielo.br/scielo.php?pid=S198177462005000200003\&script=sci_abstract\&tlng=pt. DOI: http://dx.doi.org/10.1590/S198177462005000200003. Acesso em: 27 out. 2020.

CAVACO, Maria Helena. Ofício do professor: o tempo e as mudanças. In: NÓVOA, António. (org.). Profissão professor. 2. ed. Porto: Porto Editora, 1999. p. 155-191.

CECIM, Jéssica da Silva Rodrigues; STRAFORINI, Rafael. Narrativa autobiográfica e formação docente em Geografia: reconstruindo percursos formativos a partir da narrativa da experiência. Itinerarius Reflectionis, Goiânia, v. 14, n. 2, p. 1-18, 2018. Disponível em: https://www.revistas.ufg.br/rir/article/view/52725/25808. DOI: https://doi.org/10.5216/rir.v14i2.52725. Acesso em: 27 out. 2020. 
CHISM, Nancy Van Note; LEES, N. Douglas; EVENBECK, Scott. Faculty development for teaching innovation. Liberal Education, Washington, v. 88, n. 3, p. 34-41, 2002.

CUNHA, Maria Isabel da. O tema da formação de professores: trajetórias e tendências do campo na pesquisa e na ação. Educação e Pesquisa, São Paulo, v. 39, n. 3, p. 609-626, set. 2013. Disponível em: https://www.scielo.br/scielo.php?pid=S1517-

97022013005000014\&script=sci_abstract\&tlng=pt. DOI: https://doi.org/10.1590/S151797022013005000014. Acesso em: 27 out. 2020.

ESTEVE, José Manuel. O mal estar docente: a sala de aula e a saúde dos professores. Bauru: EDUSC, 1999.

FEUERWERKER, Laura Camargo Macruz; SENA, Roseni Rosangela. Contribuição ao movimento de mudança na formação profissional em saúde: uma avaliação das experiências UNI. Interface, Botucatu, v. 6, n. 10, p. 37-49, fev. 2002. Disponível em: https://www.scielo.br/scielo.php?script=sci_arttext\&pid=S141432832002000100004\&lng=en\&nrm=iso. DOI: https://doi.org/10.1590/S141432832002000100004 . Acesso em: 27 out. 2020.

FREIRE, Paulo. Pedagogia da autonomia. Rio de Janeiro: Paz e Terra, 1999.

GIL, Antônio Carlos. Metodologia do ensino superior. São Paulo: Atlas, 2005.

HILGER, Thaís Rafaela. Aprendizagem significativa e representações sociais: aproximações teóricas. Aprendizagem Significativa em Revista, Porto Alegre, v. 6, n. 3, p. 1-19, dez. 2016. Disponível em: http://www.if.ufrgs.br/asr/artigos/Artigo_ID87/v6_n3_a2016.pdf. Acesso em: 27 out. 2020.

JUNGES, Kelen dos Santos; BEHRENS, Marilda Aparecida. Prática docente no ensino superior: a formação pedagógica como mobilizadora de mudança. Perspectiva, Florianópolis, v. 33, n. 1, p. 285-317, jan./abr. 2015. Disponível em: https://periodicos.ufsc.br/index.php/perspectiva/article/view/2175795X.2014v33n1p285/31220. DOI: https://doi.org/10.5007/2175-795X.2014v33n1p285. Acesso em: 27 out. 2020.

LEFEVRE, Fernando; LEFEVRE, Ana Maria Cavalcanti. O discurso do sujeito coletivo: um novo enfoque em pesquisa qualitativa. Caixas do Sul: EDUCS, 2005.

MARTINEZ, Maria Carmen; PARAGUAY, Ana Isabel Bruzzi Bezerra; LATORRE, Maria do Rosário Dias de Oliveira. Relação entre satisfação com aspectos psicossociais e saúde dos trabalhadores. Revista de Saúde Pública, São Paulo, v. 38, n. 1, p. 55-61, fev. 2004. Disponível em: https://www.scielo.br/scielo.php?pid=S0034-

89102004000100008\&script=sci_abstract\&tlng=pt. DOI: https://doi.org/10.1590/S003489102004000100008 . Acesso em: 27 out. 2020.

MORAES, Gustavo Simão et al. A didática no ensino odontológico: percepções de docentes. Revista da ABENO, Londrina, v. 18, n. 2, p. 27-36, 2018. Disponível em: 
https://revabeno.emnuvens.com.br/revabeno/article/view/451/392. DOI: https://doi.org/10.30979/rev.abeno.v18i2.451. Acesso em: 27 out. 2020.

NORO, Luiz Roberto Augusto et al. O professor (ainda) no centro do processo ensinoaprendizagem em Odontologia. Revista da ABENO, Londrina, v. 15, n. 1, p. 2-11, 2015. Disponível em: https://revabeno.emnuvens.com.br/revabeno/article/view/146/130. DOI: https://doi.org/10.30979/rev.abeno.v15i1.146. Acesso em: 27 out. 2020.

NORO, Luiz Roberto Augusto. A importância da aula. Revista da ABENO, Londrina, v. 15, n. 4, p. 91-99, 2015. Disponível em:

https://revabeno.emnuvens.com.br/revabeno/article/view/229/193. DOI:

https://doi.org/10.30979/rev.abeno.v15i4.22. Acesso em: 27 out. 2020.

PEREIRA, Meira Chaves; NASCIMENTO, Fabrício do. A universidade brasileira e a formação de professores para o ensino superior. Laplage em Revista, Sorocaba, v. 2, n. 2, p. 101-110, 2016. Disponível em:

https://laplageemrevista.ufscar.br/index.php/lpg/article/view/961/1187. DOI:

https://doi.org/10.24115/S2446-6220201622164p.101-110. Acesso em: 27 out. 2020.

PRYJMA, Marielda Ferreira; OLIVEIRA, Oséias Santos de. O desenvolvimento profissional dos professores da educação superior: reflexões sobre a aprendizagem para a docência. Educação \& Sociedade, Campinas, v. 37, n. 136, p. 841-857, set. 2016. Disponível em: https://www.scielo.br/scielo.php?pid=S0101-

73302016005001104\&script=sci_abstract\&tlng=pt. DOI: http://dx.doi.org/10.1590/es010173302016151055. Acesso em: 27 out. 2020.

RIOS, Izabel Cristina; SCHRAIBER, Lilia Blima. A relação professor-aluno em Medicina - um estudo sobre o encontro pedagógico. Revista Brasileira de Educação Médica, São Paulo, v. 36, n. 3, p. 308-316, 2012. Disponível em: https://www.scielo.br/pdf/rbem/v36n3/04.pdf. Acesso em: 27 out. 2020.

ROSSI, Fernanda; HUNGER, Dagmar. As etapas da carreira docente e o processo de formação continuada de professores de Educação Física. Revista Brasileira de Educação Física e Esporte, São Paulo, v. 26, n. 2, p. 323-338, 2012. Disponível em: https://www.scielo.br/scielo.php?script=sci_abstract\&pid=\$180755092012000200014\&lng=pt\&nrm=iso. DOI: https://doi.org/10.1590/S180755092012000200014. Acesso em: 27 out. 2020.

SADALLA, Ana Maria Falcão de Aragão et al. Teorias implícitas na ação docente: contribuição teórica ao desenvolvimento do professor prático- reflexivo. In: AZZI, Roberta Gurgel; BATISTA, Sylvia Helena Souza da Silva; SADALLA, Ana Maria Falcão de Aragão. Formação de professores: discutindo o ensino de Psicologia. Campinas: Alínea, 2000. p. 21-38.

SETTE-DE-SOUZA, Pedro Henrique. Motivating learners in pandemic period through WhatsApp and Google Meet. Journal of Dental Education, Washington, p. 1-2, 2020. Disponível em: https://onlinelibrary.wiley.com/doi/epdf/10.1002/jdd.12352. DOI: https://doi.org/10.1002/jdd.12352. Acesso em: 27 out. 2020. 
SOARES, Sandra Regina; CUNHA, Maria Isabel da. Formação do professor: a docência universitária em busca de legitimidade. Salvador: EDUFBA, 2010.

TARDIF, Maurice. Saberes profissionais dos professores e conhecimentos universitários: elementos para uma epistemologia da prática profissional dos professores e suas consequências em relação à formação para o magistério. Revista Brasileira de Educação, São Paulo, n. 13, p. 5-24, 2000. Disponível em:

www.ergonomia.ufpr.br/Metodologia/RBDE13_05_MAURICE_TARDIF.pdf. Acesso em: 27 out. 2020.

VOCHIKOVSKI, Laína et al. Didática no ensino superior: desafios e perspectivas dos docentes de Odontologia da Universidade Estadual de Ponta Grossa. Revista da ABENO, Londrina, v. 18, n. 3, p. 12-23, 2018. Disponível em: https://revabeno.emnuvens.com.br/revabeno/article/view/471/440. DOI: https://doi.org/10.30979/rev.abeno.v18i3.471. Acesso em: 27 out. 2020. 


\section{Rafaelly Galindo dos Santos Pereira}

Cirurgiã-dentista pela Universidade de Pernambuco, campus Arcoverde, 2019. Voluntária de iniciação científica pela mesma universidade de 2017 até 2019.

rafaellygalindosm@gmail.com

\section{Renata de Oliveira Cartaxo}

Cirurgiã-dentista pela Universidade Federal da Paraíba (2010). Especialista em Nutrição, Saúde e Educação pela Faculdade do Norte do Paraná (2015). Mestra em Saúde Coletiva e Gestão Hospitalar pela Universidade Gama Filho (2015). Doutoranda em Ciências da Saúde pela Faculdade de Medicina do ABC. Professora assistente do curso de Odontologia da Universidade de Pernambuco, campus Arcoverde, em 2017.

renata.cartaxo@upe.br

\section{Herika de Arruda Mauricio}

Cirurgiã-dentista pela Universidade de Pernambuco - UPE (2004). Especialista em Saúde Coletiva pelo Centro Universitário Maurício de Nassau - UNINASSAU (2007) e em residência multiprofissional em Saúde Coletiva pela UPE (2010). Mestra em Saúde Pública pelo Instituto Aggeu Magalhães/Fundação Oswaldo Cruz (2012) e doutora em Saúde Pública pelo mesmo instituto (2020). Professora adjunta do curso de Odontologia da UPE, campus Arcoverde.

herika.mauricio@upe.br

\section{Pedro Henrique Sette-de-Souza}

Cirurgião-dentista pela Universidade Federal do Rio Grande do Norte (2013). Mestre em Odontologia pela Universidade Estadual da Paraíba (2015), doutor em Odontologia pela mesma universidade (2018). Professor adjunto do curso de Odontologia da Universidade de Pernambuco (UPE), campus Arcoverde. Docente permanente do Programa de PósGraduação em Saúde e Desenvolvimento Socioambiental da UPE, campus Garanhuns. pedro.souza@upe.br 